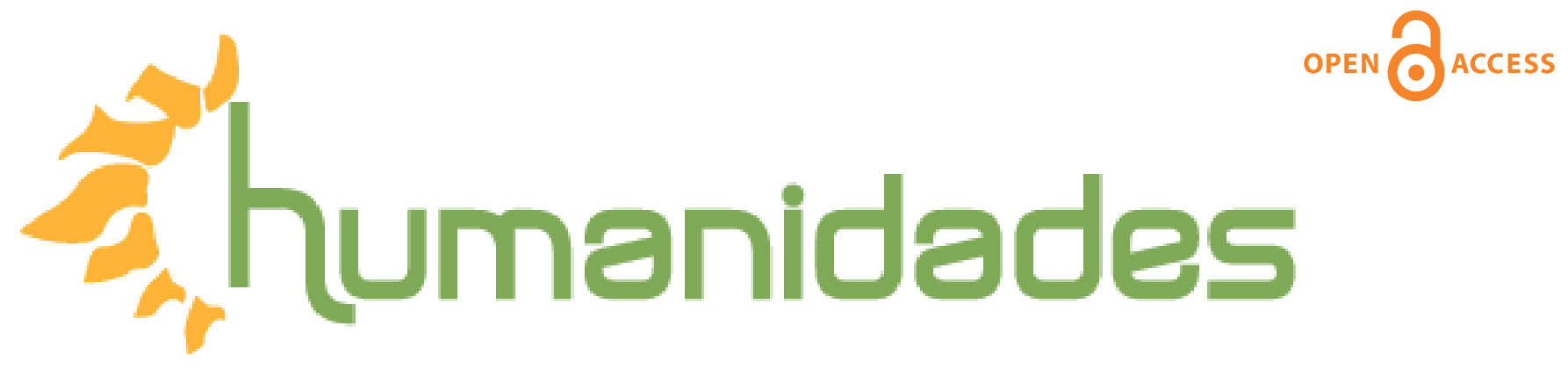

Revista de la Escuela de Estudios Generales, Universidad de Costa Rica

Julio-diciembre, $2018 \cdot$ Volumen 8 , número 2 • EISSN 2215-3934 •pp. 1-33

Recibido: 13-Setiembre-2017 Aceptado:13-Febrero-2018

\title{
lustración y circulación de ideas pedagógicas en la monarquía hispánica
}

DOI: http://dx.doi.org/10.15517/h.v8i2.33336

\section{Lic. Sebastian Domingo Perrupato}

Departamento de Historia de la Universidad Nacional de Mar del Plata, Argentina.

Correo electrónico:sperrupato@gmail.com

Todos los derechos reservados. Universidad de Costa Rica. Esta revista se encuentra licenciada con Creative Commons. Reconocimiento-NoComercial-SinObraDerivada 3.0 Costa Rica. Correo electrónico: humanidades@ucr.ac.cr / Sitio web: http://revistas.ucr.ac.cr/index.php/ humanidades 


\section{Ilustración y circulación de ideas pedagógicas en la mo- narquía hispánica}

\section{Resumen}

Los estudios sobre la Ilustración española han transitado por dos caminos bien diferenciados. Por un lado, una corriente extranjerizante que entendió que las verdaderas luces provenían del influjo francés, y por otro, un grupo de historiadores que pretendió ver en el componente católico cierta originalidad. Las dos líneas de trabajo descuidaron los complejos fenómenos de apropiación e hibridación que se dieron en la Europa moderna como correlato de la circulación de ideas que tendió a intensificarse durante el siglo XVIII. El presente trabajo intenta analizar la circulación de ideas en torno a las propuestas pedagógicas de los ilustrados españoles. La mayoría de los intelectuales españoles del siglo XVIII coincidían en la necesidad de articular redes de diálogo y comunicación entre las diferentes partes del globo; no obstante, para ello debieron hacer frente a varias dificultades: la censura, la traducción y la escasez de libros son solo algunas de ellas.

\section{Enlightenment and movement of teaching ideas in the hispanic monarchy}

\begin{abstract}
Studies on the Spanish Enlightenment have gone through two well differentiated paths. On one hand, a foreign tendency that understood that the true lights came from the French influence, and on the other hand, a group of historians that pretended to see in the Catholic component a certain originality. The two lines of work neglected the complex phenomena of appropriation and hybridization that occurred in modern Europe as a correlate of the circulation of ideas which tended to intensify during the eighteenth century. This paper attempts to analyze the flow of ideas around the educational proposals of the Spanish Enlightenment. Most Spanish intellectuals of the eighteenth century coincided in the need to articulate networks of dialogue and communication between the different parts of the globe, however for this they had to face several difficulties, censorship, translation and the scarcity of books are just some of them.
\end{abstract}

Palabras claves: Circulación de ideas , Ilustración, Monarquía hispánica, Educación
Keywords: Circulation of ideas, Enlightenment, Hispanic Monarchy, Education 


\section{Ilustración y circulación de ideas pedagógicas.}

«Esta comunicación literaria de las naciones, es indispensable para que los progresos de las ciencias sean recíprocos» (Rodríguez de Campomanes, S/F, f. 17).

\section{Introducción}

El tema de la Ilustración ha sido abordado por diferentes autores que pusieron en evidencia las particularidades de sus manifestaciones específicas en cada caso estudiado. De aquí que muchos hayan preferido hablar de ilustraciones. Incluso dentro de España se ha discutido en torno a las ilustraciones regionales: la Ilustración vasca, navarra, canaria, madrileña, entre tantas otras.

Pese a estas particularidades, como afirma Sánchez Blanco (2013) la Ilustración

marcó un rasgo distintivo en la cultura europea, como lo fue la herencia grecorromana o el cristianismo. Es más ese concepto se convierte en la señal de identidad más importante de Europa. Otras civilizaciones o países que no han pasado por el proceso de la "Ilustración" dieciochesca mantienen hoy grandes diferencias religiosas y políticas con el mundo occidental (p. 11).

Se trató entonces de un fenómeno principalmente occidental con características comunes entre las diferentes regiones y cierta difusión y permeabilidad que permiten entender la Ilustración como un proceso con condicionamientos recíprocos entre los diferentes territorios. Permítasenos nuevamente una cita del mismo Sánchez Blanco (2013) que merece la pena ser rescatada:

el nexo entre lo nacional y lo ideológico no es muy estrecho y, por lo tanto, para aquellos que niegan que en España hubiera Ilustración resulta poco convincente la integración de nuestro país en el movimiento Europeo, sobre todo porque a los españoles nos cuesta trabajo alzar la mirada por encima de la barrera de los Pirineos o alargarla más allá de la aridez de los mares circundantes y, en cambio, nos recreamos observando las particularidades locales, regionales, intelectualmente más asequibles (p. 12).

Esto no implica que el proceso fuera homogéneo y unívoco, pero sí que existieron elementos compartidos, o en el sentido de un común denominador, 
sino de una interacción basada en el conocimiento mutuo y en la influencia recíproca. Si bien podríamos admitir que en Inglaterra nació la «modernidad científica, religiosa y política» (Bacón, Locke, Newton) que después retomaría el resto del continente,

no se trata de exponer la influencia de un autor particular sobre toda Europa, como si fuera una madeja de un solo hilo. Es innegable y empíricamente observable, el trasvase de ideas a través de los canales por los que circulan informaciones y argumentos, que permiten la difusión de iniciativas $\mathrm{y}$ hacen que se sientan las mismas preocupaciones, aunque se den respuestas diversas (Sánchez Blanco, 2013, p. 13).

Como hemos sostenido en otra oportunidad, la Ilustración en la Monarquía hispánica no surge de la nada: no existió un vacío intelectual que requirió de la «importación» de ideas del extranjero. Por el contrario, la producción científico-literaria que se dio en la península desde fines del siglo XVII sentó las bases y nutrió de sentido a la apropiación que los ilustrados españoles hicieron de algunos elementos del pensamiento europeo en la dialéctica tradición - modernización (Perrupato, 2012).

Desde que Ortega y Gasset (1961) sostuvo la ausencia del «siglo educador» en España, catalogando el siglo XVIII como el «menos español de nuestra historia»(p. 600), la preocupación por los orígenes de la Ilustración española ha sido incesante. La pregunta sobre hasta qué punto fue original o copia de Francia la ilustración obtuvo diversas respuestas, llevando a un grupo de intelectuales a buscar las particularidades «nacionales» en el talante católico (Herr, 1964; Rodríguez Casado, 1951, 1962, 1965; Domínguez Ortiz, 1976, 1988, 1990; Maravall, 1979, 1991; Mestre, 1982, 1993, 1998, 2000; Aguilar Piñal, 1989, 1991, 2002, 2005).

Sin embargo, los planteamientos sobre una Ilustración católica exclusiva para el caso español tienen sus límites. Intelectuales franceses como el educador Carlos Rollin pretendían articular muchas de las ideas ilustradas con la doctrina católica. os intelectuales españoles retomarán sus enseñanzas y defenderán la enseñanza a partir de la educación católica que propugna el Abate de Fleury en su catecismo histórico. En este sentido, deberíamos 


\section{Ilustración y circulación de ideas pedagógicas.}

preguntarnos nuevamente, ¿es realmente cierto que fue el talante «católico» de la Ilustración propio del pensamiento español? ¿no existió previo a la Ilustración española un pensamiento católico «anti-luces»?

Algunos autores han hablado de las anti-luces europeas como un movimiento consolidado a lo largo del siglo XVIII con una fuerte impronta cristiana, crítico hacia la Ilustración y encabezado por autores como Fenelon, Saint Martin, Maine de Biran. Estos planteos ponen en evidencia que la originalidad católica que algunos autores han pretendido ver en el pensamiento español no era tal, o cuanto menos no era exclusiva de España. Dentro del pensamiento ilustrado encontramos estas anti-luces, «Luces en el corazón de las anti-luces (...) Anti-luces en el corazón de las luces» (Deprun, 1976/2002, p. 338).

En todo caso un gran número de importantes ilustrados de toda Europa no entiende la Ilustración como un movimiento ateísta, materialista, sino más bien como expresión de renovación cristiana, como una fase en un proceso de secularización o laicización. Esta evolución va contra la Iglesia, contra su pretensión directiva en el mundo, pero no contra la religión y fe (Jüttner, 1992, p. 129).

El cambio de dinastía a principio de siglo favoreció los vínculos entre intelectuales de ambos lados de los Pirineos, lo que se potenció un siglo después con la coronación de José Bonaparte. No obstante, los intelectuales españoles no se dedicaron a aceptar sistemáticamente todo lo que provenía del exterior, como tampoco construyeron una Ilustración católica diferenciada del resto de Europa. Se trató más bien de «un complejo fenómeno de intercambios culturales, con ideas y pensamientos que circulaban en diferentes direcciones» (Perrupato, 2012, p. 183). Se trató de un proceso complejo de apropiación, hibridación y solapamientos de ideas1.

\section{La circulación de Ideas}

Para el presente análisis partimos del concepto de «circulación de ideas» de Pierre Bourdieu (2002). Por este se entiende el proceso de emisión y recepción de las ideas desde unas regiones hacia otras, asumiendo que en este 
transcurso se van produciendo mutaciones o hibridaciones y que «el significado y la función de las obras extranjeras son determinadas tanto por el campo de acogida como por el campo original» (p. 3).

Tanto el pensamiento ilustrado español como el europeo se integran en un fenómeno más amplio en el que las ideas circulan entre las diferentes regiones y vuelven el pensamiento profundamente ecléctico. De este modo, la apropiación que los intelectuales de la Monarquía hicieron de las ideas europeas no fue el resultado de una transposición directa sino de la lectura que hicieron en un contexto y con intereses particulares.

No se trata de comprender la circulación de ideas como un mero planteamiento teórico que de modo aplicacionista se vierte al pensamiento dieciochesco español; por el contrario, los mismos ilustrados se mostraron defensores de estas ideas, por lo menos hasta la llegada de la Revolución francesa. Para Jovellanos este tema será una gran obsesión; en su diario encontramos la referencia al tema: «Respuesta a Jardine: Educación, remover los estorbos a la circulación de ideas; los mayores de la política, asustada por los progresos de la razón»(Jovellanos, 1794, p. 131).

Lo interesante es que dicha carta haya sido escrita luego de que en 1792 Cabarrús le escribiera su segunda carta Sobre los obstáculos de opinión y medio de removerlos con la circulación de luces y un sistema general de educación donde defendía la necesidad de que el gobierno establezca «la más expedita circulación de ideas para que la nación se ilustrase», debiendo proporcionar los «auxilios correspondientes a toda asociación de hombres que ponen en común deposito, y se trasladan de unos a otros, sus luces y conocimientos» (Cabarrús, 1795, p. 569).

Pero no solo para ellos; el mismo Campomanes lo entendía así en la cita que da comienzo al presente capítulo. Debemos sumar también a Olavide y la defensa que hacía de la apertura a Europa. Para estos intelectuales, las causas del retraso cultural tenían sus orígenes en el aislamiento que España había experimentado en la última centuria.

Por ello los ilustrados reclamaban una y otra vez la necesidad de abrir las 


\section{Ilustración y circulación de ideas pedagógicas.}

puertas a Europa, dando a conocer el desarrollo intelectual español de aquellos años. Campomanes reivindicaba la labor de los españoles en el extranjero en su Introducción a ciertos estudios públicos...

«con todo era mucho el número de españoles que después de haberestudiado y graduarse en el reino frecuentaban las universidades de fuera. Andrés de la Laguna enseñó la Medicina y Botánica en Flandes, y en Italia. Pedro Ciruelo las Matemáticas en Paris, el Doctor Martin Navarro Azpilcueta en Derecho canónico en Coímbra, y otras varias» (Rodríguez de Campomanes, S/F, f. 17).

En su discurso en la Real Sociedad de Amigos del País del Principado de Asturias Jovellanos defendía la idea de enviar pensionistas al exterior para que tomaran contacto con las luces europeas asegurando que de allí venían los mayores progresos y que habían contribuido a generar muchas verdades útiles

«que han desterrado del mundo muchas preocupaciones perniciosas; y a quienes las artes, la industria y el comercio de Europa deben los rápidos progresos que han hecho en este siglo. [...] Para que la sociedad pueda hacer a este país el beneficio de atraer a él las ciencias útiles, conviene que abra una subscripción para juntar el fondo necesario a dotar dos pensionistas que salgan de la provincia a estudiarlas, y adquieran viajando los conocimientos que tengan relación con el adelantamiento de las artes» (Jovellanos, 1782, p. 32).

La obra de Hervás y Panduro es paradigmática en este sentido. En su Causas de la Revolución de Francia en el año 1789 y medios de que se han valido para ejecutarla los enemigos de la religión y del Estado, defendió que los fines de la Revolución francesa eran la destrucción del cristianismo y, como consecuencia, de toda autoridad política. Al preguntarse a qué se debía tal odio, contestaba que al buscar desenfrenadamente la libertad natural, el hombre se propuso aniquilar los obstáculos que la impedían y el principal era la religión, freno a sus deseos bestiales y anárquicos. Pero la supresión de la autoridad religiosa destruyó toda Monarquía y produjo todos 
los desastres que naturalmente le siguieron (Hervás y Panduro, 1807).

Sin embargo, Hervás era un defensor acérrimo de la circulación de ideas. Él mismo mantuvo intercambios fluidos, con muchos intelectuales no solo europeos sino también orientales. Un buen ejemplo de lo que afirmamos es el intercambio que mantuvo con el alemán Wilhem von Humbolt, a quien elogiaba en sus escritos:

«Un ejemplo que yo desearía imitasen estos sabios, les propongo en el literato señor barón de Humbolt, ministro del rey de Prusia en esta corte romana: este [...] ha escrito diccionarios de que ventajosamente me he servido al fin del presente tomo, y que tenidos al empezar a escribirle [...] El dicho señor barón está actualmente cogiendo los frutos de sus tareas en aprender el vascuence, y escribir sus diccionarios, que va a comunicar a su nación con eruditos escritos» (Hervás y Panduro, 1804, p. 220).

ensión en la circulación de ideas antes y después de la Revolución francesa, parece haber sido común a todos los ilustrados. ¿Era esta contradicción producto del enfrentamiento entre modernidad y tradición? Evidentemente la defensa de la circulación era la defensa de la modernidad, una modernidad que no se entendía fuera de las relaciones entre los diferentes países europeos. Sin embargo, esto no dejaba de lado el pensamiento tradicional y el rechazo a aquellas ideas más jacobinas del pensamiento extranjero.

Un buen ejemplo de esta tensión es la relación entre Jovellanos y el británico Jardine. Luego de años de relación escribía el español en su Diario:

«No me gustan ya sus ideas políticas y menos las religiosas, distamos inmensamente en uno y en otro» Días después continuaba «A Jardine, que no apruebo sus ideas religiosas, ni es posible dejar de reconocer las que predica la naturaleza y abarca tan agradablemente la razón, ni tampoco las que defiende Mably cuya opinión, en cuanto a la guerra civil detesto, que jamás creeré que se debe procurar a una nación más bien del que pueda recibir; llevar más adelante las reforma sería ir hacia atrás» (Jovellanos, 1794, p. 154). 
erto, la modernidad tenía sus límites y estos estaban dados por la tradición y el rechazo a la Revolución francesa. No se podía permitir que España sufriera una Revolución por lo que generasen las nuevas ideas. En este sentido, el pensamiento que muchos historiadores tienen sobre la influencia de las ideas en la sociedad es el mismo que tenían los protagonistas de este proceso2.

Solo entendiendo esto se pueden explicar la censura y la Inquisición. En la época se admitía la posibilidad de que por leer a Rousseau, Montesquieu o Voltaire un pueblo se volvería revolucionario. En esta línea escribía Jovellanos en su Diario el 21 de mayo:

«Mi opinión contra el furor de los republicanos franceses es fuertemente explicado; temor que en nada produzca sino empeorar la raza humana, la crueldad erigida en sistema, cohonestada con color y formas de justicia convertida contra los defensores de la libertad» (Jovellanos, 1794, 147).

La circulación de ideas entre Europa y España (pese a sus limitaciones) se pudo canalizar por cuatro vías, cada una de las cuales otorgó (y otorga) a los historiadores un universo de análisis: 1) la presencia de las obras en las bibliotecas y las referencias en escritos ilustrados; 2) la correspondencia entre los diferentes ilustrados; 3) las traducciones; y 4) la labor desarrollada por la censura. Haremos aquí un breve repaso de las cuatro, entendiendo que no se trata de agotar el tema, debido a que no es el objeto de análisis, simplemente se trata de comprender los procesos de apropiación que realizaron los ilustrados españoles a fin de analizar hasta qué punto la tensión entre la tradición y la modernización fue el resultado de la circulación de ideas o estaba condicionada por ella.

\section{Las bibliotecas}

No podemos dejar de reconocer la lectura y el conocimiento directo que muchos ilustrados españoles tenían de las obras europeas. En sus bibliotecas se observaban las obras más relevantes del siglo XVIII, tanto españolas como extranjeras. Claro está, como escribió Chartier (1994), ue la presencia de las obras en la biblioteca no asegura que hayan sido leídas, pero sí nos abre la 
posibilidad de pensar en qué y por qué podían ser interesantes para el autor.

Las bibliotecas de los ilustrados españoles han sido trabajadas por múltiples historiadores con resultados diversos. Según Mestre, Mayans contaba con la Enciclopedia; obras de Voltaire como El Espíritu de las Leyes o las Cartas Persas, y Melanges de Litterature, d'histoire et de philosophie de D'Alambert. Según Demerson, Meléndez Valdez leyó a Condillac, Locke, Rousseau, Heinnecio, Hume, Leibniz, Marmontel, Montesquieu, Pope, Robertson, Vattel, Voltaire, etc

Estudiada por Aguilar Piñal (1984), la biblioteca de Jovellanos reunía, en 1778, 1300 libros entre los cuales 217 fueron editados en el siglo XVI; 172 en el siglo XVII, mientras 460 pertenecían al siglo XVIII. De las obras pertenecientes a su siglo, el ilustrado poseía 144 en francés, 7 en italiano, 17 en inglés y 7 en portugués. Esto pone de manifiesto no solo la preferencia a leer en el idioma original, sino el conocimiento que tenía este intelectual de la producción científico -filosófica europea.

El índice de libros encontrado en la biblioteca del Conde de Campomanes, por su parte, manifiesta una mayor preocupación por obras de carácter nacional que extranjeras, al tiempo que registra una preferencia por obras pertenecientes al siglo ilustrado4.

Más allá de la cuestión de prestigio que implicaba la posesión de una biblioteca con libros de todas las épocas, los ilustrados leían obras extranjeras. En muchos casos esto queda demostrado a través de las referencias que, escrito tras escrito, manifestaban los autores españoles de intelectuales europeos. I

Jovellanos citaba en sus obras a Newton, Bacon, Hume, D'Alambert, Condorcet, Fleury, Mirabeau, Rousseau, Voltaire y artículos de la Enciclopedia o Discurso razonado de ciencias, las artes y los oficios. Climent hacía lo propio con obras de Condillac, Verneyy otros. De este modo podríamos seguir con otros tantos ilustrados que retomaban múltiples obras europeas demostrando no solo su erudición, sino también el conocimiento que tenían de las ideas circulantes. 


\section{Ilustración y circulación de ideas pedagógicas.}

s plantea un nuevo interrogante ¿Por qué vías llegaban las obras e ideas a los ilustrados españoles? La circulación se vio favorecida por las relaciones de amistad, que potenciaron no sólo el intercambio epistolar sino también la circulación de libros. En esto nos detendremos brevemente.

\section{Las amistades}

Como mencionamos, resultan en muchos casos evidentes las lecturas que los ilustrados españoles tenían de las propuestas «adelantadas» europeas. Pero cómo llegaban estas obras a los ilustrados españoles es un poco más confuso. Las cartas y relaciones de amistad contribuyeron significativamente a esta circulación mediante constantes flujos materiales y de información, no solo a ambos lados de los Pirineos, sino también con otras partes del mundo.

Ciertamente no podemos analizar las relaciones de amistad y los encuentros que existían entre los diferentes ilustrados, dado que se carece de la documentación que lo certifique. Sin embargo, si seguimos sus itinerarios biográficos se pueden inferir muchos de los lazos de amistad existentes entre estos actores. La evidencia historiográfica más importante en torno al tema son las cartas que se escribían unos a otros. Ya sea en pos de una oda o de una crítica, las epístolas fluían en Europa intercambiando ideas y creando vínculos.

La correspondencia entre los ilustrados españoles y los extranjeros es un foco de imprescindible análisis. Pese a esto, no se cuenta con estudios que hayan explotado esta perspectiva. Como ha señalado León Esteban (1988), existe correspondencia entre Voltaire y Aranda, Olavide, Mayans y el Marqués de Miranda; de Rousseau con Ignacio de Altuna, Carrión, Fagoaga y el Duque de Alba; de D'Alambert con el Duque de Villarmosa y de Mayans con Pluer y Schomberg; pero queda aún mucho trabajo por hacer en torno al tema.

Paradigmática es quizás la amistad que tenía Voltaire con el Conde de Aranda, que lo había alabado en su diccionario filosófico, viéndose recompensado con vinos, porcelanas, paños y sedas. No es extraño tampoco que el Cándido 
de Voltaire viaje por Paraguay, cuando su creador tenía acciones en la nave fletada por el rey español en 1756 con el objetivo de transportar tropas contra los jesuitas. Los lazos de amistad no repararon simplemente en intereses intelectuales; las concesiones, privilegios y beneficios económicos que se establecían daban a las relaciones un sentido utilitarista que va siendo más marcado en el transcurso del siglo XVIII (Sánchez Blanco, 1992).

También la ya mencionada relación de Jovellanos con Jardine en la que los intercambios epistolares y encuentros se vieron favorecidos por la labor del segundo como cónsul británico. La influencia de Jovellanos sobre el inglés se hizo notar en el proyecto de fundar en La Coruña una escuela parecida al Instituto Asturiano. Como deja entrever Álvarez Valdés, seguramente Jardine se vio más interesado en Jovellanos y «deseoso de captar una personalidad tan deslumbrante» (Álvarez Valdés, 2012, p. 281). Por su parte, el asturiano se mostraba más ofuscado con algunas de sus ideas revolucionarias.

Debemos señalar, además, la riqueza y fluidez de las relaciones de amistad dentro de la Monarquía. Así las diplomacias entre los diferentes ilustrados españoles les permitían acceder a fuentes europeas. Las tertulias y reuniones en casa de Olavide por ejemplo les permitieron a otros intelectuales, como Jovellanos acceder a libros de Bacon, Hume, Montesquieu, Voltaire, Rousseau.

No es nuestro objetivo analizar aquí las redes generadas en torno a las amistades, simplemente proponer que fueron una vía efectiva de flujo de información y de formas de acceder a obras europeas (incluso aquellas prohibidas), así como también una de las preferidas para la exportación de ideas fuera de la península. Había, sin embargo, un obstáculo en la circulación que era necesario sortear: el idioma. Como veremos, no todos los ilustrados manejaban varios idiomas, lo que convirtió a la traducción en un medio significativo para la difusión de las nuevas ideas provenientes del extranjero.

\section{La traducción}

La circulación de obras del extranjero dentro de la península se dio por dos medios: por un lado, en su idioma original, para ello era necesario que alguien la hubiera traído del extranjero; por otro lado, en su versión traducida. 


\section{Ilustración y circulación de ideas pedagógicas.}

La traducción de una obra implicaba de algún modo su «masificación». Después de todo, pocos eran los que sabían leer y escribir, menos aún eran quienes lo hacían en otros idiomas.

De este modo la traducción de las obras se convirtió en la oportunidad de muchos ilustrados de segunda línea para acceder a ellas de un modo más directo. Sin embargo, los textos que se traducían debían contar con aprobación del Consejo Real para su impresión. Este requisito ofrece a los historiadores la posibilidad de analizar, no solo las obras que se traducían e imprimían, sino también aquellas que no eran aprobadas pero que evidentemente habían llegado a manos de algunos traductores.

Aguilar Piñal (1991) estimó (teniendo en cuenta los cinco primeros tomos de su bibliografía) unos 1.200 títulos traducidos de lenguas modernas europeas, estableciendo que el $65 \%$ eran del francés el $23 \%$ del italiano, 7,3\% del inglés, un 3,7\% del portugués y $1 \%$ del alemán. Según los datos que recogimos del Archivo Histórico Nacional, la proporción cambia un poco en relación a las obras de pedagogía, si bien las traducciones del francés siguen siendo preponderantes y el segundo lugar es ocupado por las inglesas, y el tercero por las italianas.

Si analizamos las actas del Consejo de Castilla para conocer cuáles fueron las impresiones realizadas en la época sobre educación, encontramos que del total de ediciones5 que solicitaban autorización para publicar entre $1740 \mathrm{y}$ 1833, casi la mitad eran permisos para imprimir traducciones mayormente del francés.

En este sentido, deberíamos preguntarnos: ¿por qué casi la mitad de los pedidos para publicar son traducciones? ¿será que esto sostiene la idea historiográfica de un siglo XVIII español pobre en producción literaria? Evidentemente debemos apuntar dos cosas: En primer lugar, quienes pedían autorización de publicar no eran en su mayoría los intelectuales españoles, sino clérigos, maestros de escuela o ilustrados de segunda línea y lo hacían casi siempre con un fin práctico. Se trataba de traducir aquellas obras que «puedan ser útil y contribuir para la mejor y más fácil enseñanza de los niños»(AHN, Consejos, Leg. 5561). 
En segundo lugar, muchas de las obras de los ilustrados españoles fueron editadas en el extranjero o en imprentas alejadas de Madrid; incluso en Francia se edita para España.

De esta forma evitaban la doble censura y podían avanzar sobre algunas ideas poco ortodoxas. Los ejemplos paradigmáticos son por todos conocidos: Hervás y Panduro publicaba su Idea dell' universo (1778-1792) en Italia, mientras Olavide hacía lo suyo en Valencia con El Evangelio en triunfo (1797).

Esto queda expresado también en la carta que Borras y Grisola escribió a Campomanes implorando la apertura de la aduana para poder introducir en el reino:

«Los ciento y noventa ejemplares que tengo detenidos en la Real Aduana de Barcelona de mi nuevo tratado sobre educación, encuadernados en cuatro tomos, solo por no estar impresos en España, entre los cuales está el que dirigí a V S excelentísima» (Borras y Grisola, 1776, f. Único).

Quizás el interés por las traducciones responda a una concepción propia de la mentalidad española del siglo XVIII que veía en España un significativo retraso en comparación con otros países europeos. Como ponía de manifiesto Rodríguez de Campomanes (s. f.), se traducían libros extranjeros porque era «preciso tomar de allí la enseñanza para no ser inferior en el cultivo de las ciencias (en las que) se ve poco adelantamiento en los estudios» (F. 14). Olavide también se mostraba pesimista por la comparación con otros reinos que «llevan dos siglos adelantados en descubrimientos y progresos» (Olavide, 1767, p. 80).

Como mencionamos previamente, un gran número de las obras sobre pedagogía que se traducían venían de Francia. Existían otras influencias que también debemos mencionar, como la inglesa, que era la que le seguía en difusión. Probablemente, la obra más traducida fue la de Locke, Tratado de educación, traducido por Don Felipe Antonio Calderón (AHN, Consejos, Leg. 5561), entre otros de los que tenemos referencia. 


\section{Ilustración y circulación de ideas pedagógicas.}

En virtud de lo antedicho debemos mencionar las traducciones que también se realizaron del italiano como es el caso de la labor de traductora que realizó Josefa Amar y Borbón por encargo de la Sociedad de Amigos del País de Zaragoza del Discurso sobre el problema de si corresponde a los párrocos y curas de aldea instruir a los labradores en los elementos de la economía campestre, acompañado del plan de Francesco Griselini y prologado por ella misma en 17836. También Juan Bautista Muñoz tradujo a Cesareo Pozzi en su Juicio del tratado de educación(AHN, Consejos, Leg. $5541)$.

Mucha menor importancia tuvieron las traducciones del alemán y del portugués, aunque consiguieron en el campo de la educación alguna relevancia. El Plan Metódico de los conocimientos humanos y los sistemas pedagógicos del Barón de Bielfeld y El nuevo Robinson de Campe (1770) fueron los alemanes más traducidos, mientras el Plan de estudios... del portugués Luis Antonio Verney fue una fuente importante sobre la que abrevaron muchos intelectuales españoles. Volveremos sobre este último más adelante.

La traducción en esta centuria no era un ejercicio sistemático y objetivo; por el contrario, era un vehículo de ideas para favorecer la función didáctico-moral que algunos atribuían a la literatura. Esto supone otorgar al traductor capacidades de censor, corrector y adaptador. De ahí que en muchas obras puedan leerse referencias a las traducciones «mejoradas» o «nacionalizadas»; es decir, con los nombres de los personajes y lugares acomodados a los españoles (Ruiz Casanova, 2000).

Pajares ha establecido un conjunto de principios que situarían a las traducciones en la frontera entre la manipulación y la norma (Pajares, 1994). El autor ha constatado numerosas diferencias entre los originales y sus versiones traducidas, tanto por supresión como por adición. Entre las primeras, hay supresiones de críticas de tipo social y político, de alusiones a la religión, de referencias sexuales. Las adiciones van en el sentido de una insistencia en la lección moral. En cualquier caso, se constata un intento de adecuación a las costumbres españolas, y una atenuación del realismo de los relatos extranjeros. Evidentemente estamos en presencia de un tipo de apropiación de los discursos, caracterizado por la manipulación de los 
documentos traducidos.

La problemática de la apropiación quedaba expresada en las máximas para la traducción que Covarrubias elaboró según las cuales: a) no debía tocarse el orden de las cosas y pensamientos; b) debía conservarse el orden de los conceptos; c) se debían conservar los períodos, aunque fueran muy largos; d) debían conservarse todas las conjunciones; e) había que colocar los adverbios junto a los verbos. Empero terminaba diciendo que todo esto se podía obviar si «el sentido lo exige para la claridad, o el sentimiento para la viveza, o la armonía para el agrado» (en Aragón Fernández, 1991, 357).

También Vargas Ponce, entendía esto cuando en su Declamación contra los abusos introducidos en el castellano, calificaba la traducción como «un oficio, un comercio, una manía, un furor, una epidemia y una temeridad y avilantez» (Vargas Ponce, 1791, p. 40).

En todo este proceso de cambios no estaba ausente, como apuntaba Pajares, la interferencia más asociada al tamiz de las versiones intermediarias en las que tan a menudo llegaron los textos ingleses y alemanes a España en el XVIII. Muchas de estas obras no eran leídas en su idioma original, sino en traducciones del francés que era el idioma más conocido por los ilustrados, lo que generaba una mediación que muchas veces tergiversaba el discurso.

\section{La censura}

La censura se convirtió en uno de los medios favoritos para la regulación de las lecturas y en uno de los filtros más significativos en cuanto a la circulación de ideas. El hecho de que libros como el Emilio de Rousseau hayan sido prohibidos no implica que no hayan sido leídos. Sin embargo, la aparición de obras extranjeras en los listados de libros prohibidos tenía particular énfasis, siendo las obras francesas las más censuradas. ¿Por qué estos libros eran prohibidos? ¿Quiénes prohibían los libros? ¿Frenaba la circulación de ideas dentro de España esta política? ¿Tenía la misma tenacidad la censura en todas las regiones españolas?

Tanto los diversos índices pontificios como los hispanos, y con frecuencia los 


\section{Ilustración y circulación de ideas pedagógicas.}

pastorales de los obispos, expresaban el carácter de las obras prohibidas. Tanto el Consejo de Castilla como el Tribunal de la Inquisición con sus índices y catálogos formaron una barrera sustancial que se intensificó luego de la Revolución francesa.

Evidentemente la Revolución potenció el proceso de censura. A partir de 1789 se prohibieron libros y materiales que hasta entonces eran de libre circulación. Durante la primera mitad del siglo XVIII el Estado se limitó a recordar las Cédulas Reales sobre la censura de libros. Felipe V y Fernando VI no expidieron ninguna normativa al respecto, sino que como afirma Esteban León (1988) «se limitaran a recordar lo legislado» (p. 138).

La segunda mitad del siglo tuvo caracteres distintos en relación a la censura. En Noviembre de 1752 se prohibió bajo pena de muerte la introducción y venta de libros extranjeros, al tiempo que se penaba con cien mil maravedíes y pérdida de libros a quienes los trajeran y pusieran a la venta sin que precediera la tasa de los Consejos (Eguizabal, 1897, pp. 20-21). En esta línea fue la privación a los obispos del imprimatur (1773)7.

La Revolución francesa no hizo más que profundizar esta perspectiva. Una de las primeras medidas del gobierno fue suprimir las noticias procedentes desde Francia. La Gazeta de Madrid, por ejemplo, no mencionó la convocatoria a Estados Generales, en los primeros días de Junio de 1789 el único reflejo de la realidad francesa en el periódico mencionado fue el entierro del Delfín y el viaje de la Corte a Marly (Gazeta Madrid, 03/07/1789, p. 458). De los días de la Revolución sólo se recogió una Real Ordenanza del 21 de julio relativa a la organización del Consejo de Guerra (Gazeta Madrid, 04/08/1789, p. 529) y la imposición del capelo cardenalicio a un obispo el 26 de Julio en Francia (Gazeta Madrid, 11/08/1789, p. 545).

Las noticias de la Revolución llevaron al gobierno de Floridablanca a profundizar en la prohibición de introducir libros extranjeros, dictándose numerosas resoluciones tales como la del 24 de Febrero de 1791 o la Real Orden de 15 de Julio de 1792, que disponían la censura de libros sobre revoluciones y la nueva constitución de Francia respectivamente (Novísima Recopilación, 1805, Ley XIII). La Real Orden del 14 de octubre de 1792 centralizó la censura de 
libros extranjeros colocando en los Registros de Aduanas «Dos censores, uno Real y otro, comisario de la Inquisición» (Novísima Recopilación, 1805, Ley XIV). Como ha señalado oportunamente Sánchez Blanco (2013), durante el gobierno de Carlos IV la tendencia católica de la Ilustración adquirió nuevos bríos.

Paralela a la censura gubernamental estaba la eclesiástica (quizás más estricta que la primera) que organizó la Inquisición en tribunales provinciales, tribunal de la corte y Consejo Supremo. El examen de los calificadores concluía: nihil obstat o imprimatur, si la obra podía publicarse o in totum o expurguetur, si era condenada (León Esteban, 1988, p. 136).

Pese al recrudecimiento de las medidas de censura8, ni el gobierno, ni el poder eclesiástico podían impedir la introducción y lectura de obras extranjeras en España. En términos de Foucault (1980) se trataba de un poder que resistía, una suerte de contrapoder de algún modo incontenible que entraba en tensión con el poder ejercido desde las instituciones y que tendía a desgastarlo.

Según Esteban León, cualquier intelectual de mediados de siglo podía disponer, por ejemplo, de las Memorias literarias de Paris (1751) de Ignacio de Luzán, especie de breviarios de la literatura contemporánea francesa; o de la Década Epistolar sobre el estado de las letras en Francia (1781) del Duque de Almodóvar, donde se pasaba revista a los principales enciclopedistas; también del Origen progreso y estado actual de toda literatura (1748-1806) del Abate Juan Andrés con manifiesta admiración por Locke, Montesquieu, Condillac, Rousseau, Voltaire y D'Alambert o el Correo General histórico literario y económico (1763) de Nipho donde se daba cuenta de los principales avances en torno al campo de las artes, la economía y las ciencias en Francia, Holanda, Alemania, Italia y demás provincias europeas (León Esteban, 1988).

A esta nómina podría agregarse al padre Feijoo (1774) con sus Cartas Eruditas para el conocimiento y refutación de Rousseau; a López Núñez de Paralveja que en sus Lecciones preliminares del curso de estudios (1786) trabajaba a Condillac; el Compendiode la Obra Inglesa intitulada Riqueza de 


\section{Ilustración y circulación de ideas pedagógicas.}

las Naciones (1792) de Carlos Martínez de Irujo, en la que se ponía atención en la figura de Condorcet. Defourneaux (1973) aportó una lista de personas e instituciones que gozaron de licencia para leer libros prohibidos. Además, había instituciones como las Sociedades Económicas que poseían esa licencia. Jovellanos mismo, según cuenta en carta a Jardine, habría pedido una licencia para que el Instituto Asturiano poseyera toda clase de libros prohibidos, aunque con separación y facultad de que fueran leídos sólo por los maestros (Álvarez Valdés, 2012, p. 279).

El imprentero Pedro Marín se quejaba en 1777 de que los libros prohibidos corrían clandestinamente, «se buscan a todo precio se leen con ansia y con anhelo y sin la menor licencia gustan hasta las damiselas y jóvenes su doctrina con aquella hambre que excita con apetito desarreglado la misma novedad y prohibición» (Sánchez Agesta, 1953, p. 95).

La importancia de la censura ha sido remarcada por la historiografía en los últimos años y ampliamente trabajada. Nuestra intención fue sólo poner en evidencia uno más de los mecanismos para el estudio de la circulación de ideas pedagógicas. Este análisis nos abre nuevos interrogantes: ¿Por qué la mayor parte de las obras censuradas eran de origen francés? ¿Era el temor a la Revolución lo que marcaba el carácter de la censura? Esto explicaría que la censura se hubiera intensificado luego de 1789. ¿Veían los contemporáneos que las luces francesas tendían a la secularización como lo entendieron muchos historiadores españoles? ¿Explica esta secularización de las teorías pedagógicas francesas la labor de la censura? Profundizaremos sobre estas últimas cuestiones en el apartado siguiente.

\section{Conclusiones}

Jean Jacques Rousseau escribía en 1767 sobre la necesidad de articular texto y contexto y no volver las propuestas ilustradas en meras formas aplicacionistas en regiones para las que no fueron pensadas.

«En toda clase de proyecto hay que considerar dos cosas: primeramente, la bondad absoluta del proyecto; en segundo lugar, la facilidad de la ejecución. Respecto al primer extremo, es suficiente, para que el proyecto sea admisible y practicable en sí mismo, 
ue cuanto tenga de bueno esté en la naturaleza de la cosa; aquí, por ejemplo, que, la educación propuesta sea conveniente al hombre, y bien adaptada al corazón humano. La segunda consideración depende de las relaciones dadas en determinadas situaciones: relaciones accidentales a la cosa, las cuales, como consecuencia, no son necesarias y pueden variar al infinito. De esta forma, tal educación puede ser practicable en Suiza y no serlo en Francia» (Rousseau, 1762, p. 33).

Efectivamente, como escribe Bourdieu, texto y contexto no circulan juntos, los textos circulan sin su campo de producción y al insertarse en un campo diferente son resignificados (Bourdieu, 2002, p. 2). Los usos e interpretaciones de los textos se inscriben en las prácticas específicas que los producen. Se trata entonces de prestar atención a las condiciones y a los procesos que llevan las operaciones de construcción del sentido, de reconocer que ni las inteligencias ni las ideas son descarnadas y que las categorías dadas como invariables deben construirse en las discontinuidades de las trayectorias históricas. En palabras de Chartier (1992):

«La operación de construcción de sentido realizada en la lectura como un proceso históricamente determinado cuyas modalidades y modelos varían según el tiempo, los lugares, los grupos. (...) las significaciones de un texto dependen de las formas a través de las cuales es recibido y apropiado por sus lectores» (p. 51).

La Monarquía hispánica se encontraba a fines de siglo, como gran parte de Europa, en un momento de transición y cambio con un sistema social estamental en evidente crisis. Con una sociedad aún muy aferrada a la religiosidad católica, parecería impensable que un fenómeno en principio secular como la Ilustración pudiera desarrollarse. De aquí la necesidad de muchos historiadores de plantear la autenticidad del fenómeno para España en el carácter católico. Sin embargo, el análisis en conjunto con algunas de las obras europeas revela que esto no es necesariamente así.

La tradición de los novatores, la producción científico-literaria de principio de siglo y las características de una Monarquía en franca decadencia 


\section{Ilustración y circulación de ideas pedagógicas.}

redefinieron las obras europeas y les otorgaron nuevos sentidos muchas veces alejados a su sentido original.Podemos, a modo de síntesis, recapitular la circulación de ideas en la Monarquía hispánica del siglo XVIII en torno a algunas cuestiones que, aunque desiguales -ya que no son tomadas del mismo modo por todos los intelectuales españoles-, se desprenden de la investigación presentada:

1)A lo largo del siglo XVIII los intelectuales europeos intentaron, por medio de reformas, modernizar sus reinos. En este sentido, la educación fue, junto con la economía, uno de los aspectos a los que más se han abocado, proponiendo una educación para la vida que instruyera al pueblo en los medios útiles para la Monarquía. En esto no parece haber disonancia entre las propuestas españolas y las del resto de Europa.

2) Los postulados de Locke sobre el origen del conocimiento y el lugar que la experiencia tiene en él han permeado, sin duda, las propuestas de los diversos intelectuales europeos. Tanto en Francia como en España estas ideas derivaron en la necesidad de que la educación partiese de las necesidades e inquietudes del educando. No obstante, como hemos sostenido, resulta muy difícil advertir si la llegada de estas ideas a la Monarquía hispánica fue producto de la lectura del mismo Locke o de lo que otros ilustrados franceses interpretaron de él.

3) También en muchos preceptos roussonianos paren coincidir los ilustrados de ambos lados de los Pirineos. Quizás de todos el más significativo sea la gradualidad en el aprendizaje del niño y el descubrimiento de la infancia que obligó a muchos intelectuales a pensar sus propuestas a partir de la edad de los infantes.

4) El tema de la educación femenina no parece hallar acuerdo dentro de la Monarquía hispánica. Mientras algunos intelectuales defienden la incorporación de la mujer a la formación, otros continúan plantando su exclusión. Sin embargo, ambas posiciones parecen coincidir en que la mujer debía estar fundamentalmente abocada a la familia. Tampoco coinciden los planteos en Europa al respecto: así como en el siglo XVII Comenio defiende la educación igualitaria entre hombre y mujeres, en pleno siglo XVIII, Rousseau 
propone para Sofia una educación profundamente conservadora.

5) Quizás el aspecto en el que más se note la diferencia entre las propuestas españolas y las del resto de Europa sea en torno a la educación pública. En este sentido, autores como Rousseau o Condorcet defendieron la idea de una educación pública en manos del Estado, apartada de la Iglesia y orientada fundamentalmente a formar ciudadanos. En contraposición, la mayor parte de los ilustrados españoles defienden la enseñanza en el seno de la Iglesia. El mismo Jovellanos, pese a estimar que la educación debía ser impartida por laicos, terminará dejándola en manos del clero, al no encontrar otras personas formadas (Jovellanos, 1795). Como hemos señalado en otra oportunidad: "Los españoles dieciochistas se cuidaron mucho de no entrar en coalición con la Inquisición. Pese a ello encontramos propuestas como la de Cabarrús que creyendo firmemente en la laicidad de la enseñanza intentó apartar a la Iglesia de la educación por todos los medios posibles"(Perrupato, 2012, p. 193).

La educación que promulgaban estos intelectuales no se alejaba demasiado de la sociedad estamental, a diferencia de las propuestas francesas. Sánchez Llama ha afirmado que a:

«Los ilustrados españoles solo les interesaba una "instrucción pública"dirigida y enfocada hacia unas materias muy específicas que en ningún modo deberían permitir una crítica del orden estamental vigente. Por el contrario, Condorcet y posteriormente Kant, entendían que considerar al hombre como un ser sensible, capaz de formar razonamientos y de adquirir ideas morales, favorecía inevitablemente el asentamiento del igualitarismo social» (Sánchez Llama, 1990, p. 75).

Esto mismo parece haber entendido Maravall (1986) en su artículo Los límites estamentales de la educación en el pensamiento ilustrado. Sin embargo, la crítica al régimen estamental fue una constante desde siglos anteriores. Si no fuera así, no se explicaría la necesidad de una reforma educativa en la que se intentase legitimar el sistema estamental (Perrupato, 2007). 


\section{Ilustración y circulación de ideas pedagógicas.}

6) Podemos destacar la acogida que tuvo la propuesta de Verney, entendiendo no solo que la proximidad cultural entre España y Portugal explicaría por qué en determinado contexto cultural ciertas ideas tuvieron mayor eco, sino también que su propuesta resultaba funcional a los intereses políticos de una Monarquía reformista. El proceso de apropiación fue obviamente singular en relación a las características culturales de cada región.

7) Como se mencionó previamente, observamos que la Ilustración europea no circulaba por una sola vía. Así la Ilustración francesa no llegaba a España sólo por las lecturas que los españoles tuvieron de las obras francesas, sino que también por las lecturas que hicieron de ellas los ingleses, italianos y alemanes. Por su parte, las obras inglesas no llegaban a España solo por la lectura de autores de esta nacionalidad, sino que también con mediaciones francesas, portuguesas, e italianas, entre tantas otras. Se trata de entender que la recepción de ideas en España fue parte de un complejo fenómeno en el que se recibían ideas directa e indirectamente, es decir, con mediaciones, y que al mismo tiempo España se transformaba en difusora de ideas.

8) Las ideas en España tampoco parecen haber tenido una dirección marcada, sino que circulaban en muchas direcciones entre los diferentes centros regionales. Ciertamente determinadas zonas (quizás por sus lazos comerciales, quizás por su proximidad cultural) tuvieron más relaciones con el resto de Europa, lo que les permitió intensificar el flujo de ideas. En este sentido cabría preguntarse: ¿El papel de la censura tuvo la misma intensidad en todas las zonas de España?

Evidentemente la actuación de la censura fue muy importante y puso un freno a la circulación de ideas, pero como ha afirmado Hazard (1991):

«A nuevas barreras nuevas brechas, incluso en el país menos permeable, España, acaba siempre por penetrar el pensamiento heterodoxo, a veces en las formas menos previsibles: una amistad personal, con tal autor extranjero, a quienes ha conocido en otro tiempo durante un viaje; una correspondencia en apariencia anodina, pero en la que se deslizan algunas frases reveladoras; la reseña publicada por un periódico que indignándose contra las ideas que refuta, empieza por exponerlas: todo esto independiente del comercio y del contrabando» (p. 91). 
advertir que los flujos de las ideas pedagógicas se dieron con diferente intensidad en diversas direcciones hacia adentro y hacia afuera de la península, desde los países europeos hacia España y desde esta hacia el resto de los territorios europeos. Incluso dentro de la Monarquía Hispánica existió circulación entre las diferentes regiones o entre colonias y metrópolis.

La circulación no presentó, sin embargo, flujos continuos y existieron direcciones en las que el flujo de ideas fue más marcado que otras. Las traducciones, por ejemplo, nos dan una idea al respecto acerca de la intensidad de estos flujos, entre los que sobresale la influencia francesa.

Ya hemos mencionado la tendencia historiografía que intentó advertir que todo lo nuevo y vivificante de la Ilustración provenía de la importación de ideas del resto de Europa (fundamentalmente de Francia). Creemos necesario argumentar que no todas las tendencias de modernización provenían de Francia o Inglaterra, sino que también se daban en el seno de la propia España, integrándolas en un sistema mucho más complejo en el que operaba un triple enfrentamiento entre 1) una propuesta educativa radical, altamente secularizadora y modernista entre los que podemos mencionar a Francisco Cabarrús, José Vargas y Ponce y Manuel Quintana; 2) Una educación anti-moderna reaccionaria al modernismo filosófico, que cuenta con representantes de la talla de Fernando de Ceballos, Francisco Alvarado o Juan Pablo Forner; y 3) una tendencia que sintonizaba determinados aspectos de las "nuevas ideas" integrándolos en una concepción cristiana más secular entre los que cabe mencionar a Pedro Campomanes, Cándido Trigueros, Lorenzo Hervás y Panduro y Gaspar de Jovellanos.

Contrariamente a lo que venimos desarrollando toda una línea de historiadores ha sostenido que existió una significativa adhesión de muchas de las ideas españolas a las extranjeras en torno a la modernización pedagógica y secularización de la educación. En esta dirección Emilio Redondo (2001) ha afirmado que

«La Ilustración -en sus vertientes francesa e inglesa- contribuyó decisivamente a desencadenar en España el proceso secularizador. La influencia cultural e ideológica de la nación vecina-compartida 


\section{Ilustración y circulación de ideas pedagógicas.}

con la inglesa- se canalizó con cierta facilidad -aunque no sin polémica-, a través de las nuevas estructuras políticas y el nuevo estilo, encarnados en la dinastía borbónica. El rígido racionalismo de la Ilustración fue la Filosofía política que inspiró en sustancia el reformismo borbónico español. Había en la Filosofía política "Ilustrada" una clara conciencia -cristalizada con frecuencia en formulaciones utópicas de que las reformas políticas, económicas y sociales, necesitaban, para su viabilidad y desarrollo, el concurso de un eficaz sistema educacional» (p. 490).

Entendemos que esta postura niega la posibilidad de un planteo vernáculo y secular español, al tiempo que entiende la modernización y la secularización que esta conlleva como de importación francesa. Lo que hemos manifestado, y continuaremos reafirmando, es que existen elementos para entender, en primer lugar, que los procesos de apropiación fueron mucho más complejos que la linealidad pretendida (Francia-España).

En segundo lugar, que existió un pensamiento español moderno (y por lo tanto secular) que hundió sus raíces en las propuestas de los Novatores y adquirió relevancia en la segunda mitad de siglo. La dialéctica tradiciónmodernización no se traduce en una dialéctica español - extranjero; por el contrario, ambas forman parte del mismo proceso de circulación que conllevaba tanto fenómenos modernos como tradicionales.

\section{Notas}

1 El concepto de hibridismo cultural ha sido trabajado por Peter Burke (2010), quien entiende que se trata de un encuentro cultural. Encuentro que implica no solo bilateralidades simétricas, sino también fusiones, sincretismos, adaptaciones, circularidades, traducciones, segregaciones y resistencias.

2 Esta linealidad fue marcada por Mornet (1969) y desmitificada por Chartier (1995).

3 Los datos corresponden a Mestre, 1984 y Demerson, 1971. 
4 Catalogo de libros pertenecientes a esta biblioteca 1791, FUE (Fundación Universitaria española) Archivo del Conde de Campomanes.

5 La sección Consejos del Archivo Histórico Nacional cuenta con 33 expedientes sobre el tema. De estos 15 pertenecen a traducciones mayormente del francés. AHN, Consejos, Leg. 5552, 55 (1786/1788); Leg. 5561, 27 (1796/1798); Leg. 5548, 14 (1784/1797); Leg. 5551, 6 (1785/1789); Leg. 5532, 107 (1790); Leg. 5537, 87 (1775/1783); Leg. 5545, 8 (1780); Leg. 5563, 60 (1799/1804); Leg. 5550, 22 (1785/1791); Leg. 5555, 40 (1784/1789); Leg. 5528, 20 (1758/1803); Leg. 5544, 5 (1779; Leg. 5563, 32 (1799); Leg. 5532, 21 (1770); Leg. 5536, 22 (1774/1775); Leg. 5545, 41 (1780); Leg. 5572, 96 (1833); Leg. 5557, 11 (1791/1792); Leg.5571, 25 (1831/1832); Leg. 5541, 39 (1778); Leg. 50633, 11 (1738); Leg. 5558, 108 (1792); Leg. 5571, 30 (1831/1833); Leg. 5532, 40 (1770); Leg. 5561, 17 (1796); Leg. 50636, 54 (1740); Leg. 5546, 126 (1782);Leg. 5563, 4 (1799); Leg. 5560, 60 (1794/1796); Leg. 5544, 30 (1779); Leg. 5552, 141 (1785/1803); Leg. 5779, 10 (1801); Leg. 5555, 80 (1789/1790).

6 raducción de Josefa Amar y Borbón por encargo de la Sociedad de Amigos del País de Zaragoza del Discurso sobre el problema de si corresponde a los párrocos y curas de aldea instruir a los labradores en los elementos de la economía campestre, acompañado del plan de Francesco Griselini. Prologó la edición en 1783, Blas Miedes, impresor de la Real Sociedad, BNE. 2/64991.

7 La misma se dio por Cédula del Consejo el 20 de Abril de 1773 y establecía que las licencias de impresiones solo podían ser otorgadas por el Consejo y que la censura eclesiástica solo debían informar si el escrito tenía ono alguna cosa contra la religión, dogmas o buenas costumbres sin concluir con el imprimatur ni ninguna otra leyenda que implicase autoridad jurisdiccional para la impresión. Esta Cédula fue refrendada el 1 de Febrero de 1778. (Novísima recopilación, 1805, Leyes XXVIII y XXIX)

8 Comprobable en el control sobre libros extranjeros (20 de julio de 1791), la suspensión de periódicos no oficiales (24 de Febrero de 1791), el aumento de los poderes de la Inquisición y el cambio de postura ante la política 


\section{Ilustración y circulación de ideas pedagógicas.}

ilustrada, con la prisión y destitución de Campomanes y el destierro de Jovellanos (Herr, 1971).

\section{Referencias}

Aguilar Piñal, F. (1984) La biblioteca de Jovellanos 1778. Madrid: CSIC.

Aguilar Piñal, F. (1989) «La ilustración española entre el reformismo y el liberalismo», en La Literatura española de la Ilustración: Homenaje a Carlos III. Madrid: Universidad Complutense, pp. 39-51.

Aguilar Piñal, F. (1991) Introducción al siglo XVIII. Madrid: Júcar.

Aguilar Piñal, F. (2002) «Ilustración y Despotismo ilustrado», en E. Palacios Fernández, (Coord.) Félix María de Samaniego y la literatura de la Ilustración. Madrid: Ediciones Laberinto, pp. 21-49.

Aguilar Piñal, F. (2005) La España del absolutismo ilustrado. Madrid: Espasa.

Álvarez Valdés, M. (2012) Jovellanos: vida y pensamiento. Oviedo: Ediciones Nobel.

Aragón Fernández, M. (1991) «Una teoría de la traducción en el siglo XVIII», en Donaire, M. y Lafarga, F. (Eds.) Traducción y adaptación cultural: España-Francia (pp. 531-539), Oviedo: Universidad de Oviedo.

Bourdieu, P. (2002) «Les conditions sociales de la circulation internationale des idées». Actes de la Recherche en Sciences sociales, (145), 1-10. Recuperado de: https://es.scribd.com/document/152432895/Bourdieu-Pierre-Las-Condiciones-Sociales-de-La-Circulacion-Internacional-de-Las-Ideas.

Burke, P. (2010) Hibridismo cultural. Madrid: Akal.

Chartier, R. (1992) El mundo como representación. Barcelona: Gedisa. 
Chartier, R. (1994) Libros, lecturas y lectores en la Edad Moderna. Madrid: Alianza.

Chartier, R. (1995) Espacio público, crítica y desacralización en el siglo XVIII. Los orígenes culturales de la Revolución francesa. Barcelona: Crítica.

Defourneaux, M. (1973) Inquisición y censura de libros en la España del siglo XVIII.Madrid: Taurus.

Demerson, G. (1971) Don Juan Meléndez Valdez y su tiempo (1754-1817). Madrid: Taurus.

Deprun, J. (1976/2002) «Las Anti-Luces», en Y. Belaval, Racionalismo, Empirismo, Ilustración. Madrid: Siglo XXI, pp. 337-350. Domínguez Ortiz, A. (1976) Sociedad y estado en el siglo XVIII español. Barcelona:Ariel.

Domínguez Ortiz, A. (1988) Carlos III y la España de la Ilustración. Madrid: Alianza.

Domínguez Ortiz, A. (1990) Las claves del despotismo ilustrado, 1715-1789. Barcelona: Planeta.

Eguizabal, J. (1897) Apuntes para la Historia de la legislación española sobre la imprenta.Madrid: Imprenta de Yenes.

Foucault, M. (1980) Microfisica del poder. Madrid: ediciones de la Piqueta.

Hazard, P. (1991) El pensamiento europeo en el siglo XVIII. Madrid: Alianza.

Herr, R. (1964) España y la revolución del siglo XVIII. Madrid: Aguilar.

Herr, R. (1971) España y la Revolución del Siglo XVIII. Madrid: Aguilar. 


\section{Ilustración y circulación de ideas pedagógicas.}

Jüttner, S. (1992) «El historiador filósofo, un mito político del absolutismo ilustrado», en M. Tietz (Ed.) La secularización de la cultura española en el siglo de las luces. (pp. 113-129), Wiesbaden: Herzog Agust Bibliohek.

León Esteban, L. (1988) «Las Obras "Ilustradas" Sobre la educación y su recepción en España», Revista de educación, núm. extraordinario, pp. 135-160.

Maravall, J. (1986) «Los limites estamentales de la educación en el pensamiento ilustrado», Historica das Ideias, 8.

Maravall, J. (1979) "Espíritu burgués y principio de interés personal en la Ilustración española”, Hispanic Review, 47(3), 291-325.

Maravall, J. A. (1991) Estudios de la historia del pensamiento español (Siglo XVIII).Madrid: Mondadori.

Mestre, A. (1982) «Corrientes interpretativas actuales de la Ilustración española», en AAVV. España a finales del siglo XVIII. Tarragona: Ediciones de la hemeroteca, pp. 85-96.

Mestre, A. (1984) «Inquisición y corriente ilustrada», en B. Escandell Bonet, y J. Pérez Villanueva, (dirs.) Historia de la Inquisición en España y América. (pp. 12-52), Madrid: BAC.

Mestre, A. (1993) La Ilustración. Madrid: Sintesis.

Mestre, A. (1998) La Ilustración española.Madrid: Arco.

Mestre, A. (2000) «Caracteres especificos de la Ilustración española». Conferencia en la Real Sociedad Económica de Amigos del País. Valencia: Universidad de Valencia.

Mornet, D. (1969) La pensée française au XVIIIe siècle. París: A. Colin. 
Olavide, P. (1767) Plan de estudios para la Universidad de Sevilla. Compilación y Estudio preliminar de Francisco Aguilar Piñal, Barcelona: Ediciones de cultura popular, 1969.

Ortega y Gasset, J. (1961) «El siglo XVIII educador», en Obras Completas. Madrid, Revista de occidente, T. II.

Pajares, E. (1994) «La traducción inglés-español en el siglo XVIII: ¿Manipulación o norma estética?», en F. Eguiluz, (Ed.) Trasvases culturales: Literatura, cine, traducción. (pp. 385-394) Vitoria: Universidad de País Vasco.

Perrupato, S. (2007) «La desintegración de órdenes en la España Moderna, una aproximación a lo que la literatura de la época nos revela de ella», en Actas de IV y $V$ Congreso de Estudiantes de Letras. (pp. 150-155), Mar del Plata, Suarez. ।

Perrupato, S. (2012) «Entre el naturalismo y la tradición. Un estudio comparativo entre la propuesta pedagógica de los ilustrados españoles y Rousseau», Avances del Cesor, (9), 175-194

Redondo, E. (2001) Introducción a la Historia de la educación. Barcelona: Ariel. Rodríguez Casado, V. (1951) «La revolución burguesa del siglo XVIII español», Arbor, 61, 5-30

Rodríguez Casado, V. (1965) Conversaciones de Historia de España. Barcelona: Planeta.

Rodríguez Casado, V. (1962) La política y los políticos en el reinado de Carlos III.Madrid: Rialp.

Ruiz Casanova, J. (2000) Aproximación a una historia de la traducción en España. Madrid: Cátedra.

Sánchez Agesta, L. (1953) El pensamiento político del despotismo ilustrado. Madrid: Instituto de Estudios Políticos. 
Ilustración y circulación de ideas pedagógicas.

Sánchez Blanco, F. (1992) «Una ética secular: la amistad entre los ilustrados», M. Tietz (Ed.) La secularización de la cultura española en el siglo de las luces. (pp. 169-187), Wiesbaden: Herzog Agust Bibliohek.

Sánchez Blanco, F. (2013) La Ilustración y la unidad cultural europea. Madrid: Marcial Pons.

Sánchez Llama, I. (1990) «La recepción de la Filosofía Ilustrada en España», Anuario de la Sociedad Española de Literatura General y Comparada,8, 75-84.

\section{Literatura consultada.}

Amar y Borbón, J. (1783) (Trad.) Discurso sobre el problema de si corresponde a los párrocos y curas de aldea instruir a los labradores en los elementos de la economía campestre, Blas Miedes, impresor de la Real Sociedad.

Borras y Grisola, J. (1776) Carta a Campomanes suplicando se le autorice a introducir en España los ejemplares de una obra suya sobre educación. Roma, 21 de Marzo, FUE, Archivo

Conde de Campomanes.Cabarrús, F. (1795) «Sobre los obstáculos que la naturaleza, la opinión y las leyes a la felicidad pública», en Biblioteca de Autores Españoles. Madrid: Rivadeneyra, 1870.

Covarrubias, S. (1798) (Trad.) Las aventuras de Telémaco, hijo de Ulises. Madrid: Imprenta Real.

Feijoo, B. (1774) Cartas Eruditas. Madrid: Imprenta de Pedro Marín, t. IV, Carta 18. Gaceta de Madrid, $\mathrm{N}^{\circ}$ 62, 64, 53.

Hervás Panduro, L. (1804) Catálogo de las lenguas. Madrid: Imprenta de R. A. de Beneficencia. 
Hervás Panduro, L. (1807) Causas de la Revolución de Francia en el año 1789 y medios de que se han valido para ejecutarla los enemigos de la religión y del Estado. Madrid: S/E.

Jovellanos, G. (1782) «Discurso pronunciado por el Señor D. Gaspar de Jovellanos, del consejo de S. M. en el de las Ordenes, socio honorario y de número de la Real Sociedad de Amigos del País del Principado de Asturias, y su actual Director», Oviedo 6 de Mayo, en Obras publicadas e inéditas de D. Gaspar Melchor de Jovellanos. Madrid: Atlas, 1952.

Jovellanos, G. (1794) «Diario», en Obras de D. Melchor Gaspar de Jovellanos. Madrid: Imprenta de los sucesores de Hernando, 1915. pp. $154-152$

Jovellanos, G. (1795) «Informe de la sociedad económica de Madrid al Real y Supremo Consejo de Castilla en el expediente de ley agraria», en P. Peñalver Simo (Ed.) Jovellanos obras sociales y políticas. Madrid: Publicaciones españolas, 1962.

Novísima recopilación de las leyes de España. (1805) Madrid: Imprenta real. Rodríguez de Campomanes, P. (S/F) Introducción a ciertos estudios públicos con su plan o diseño de las materias que había de tratarse $y$ de cómo tocarlas, Manuscrito sin fecha, FUE, Archivo Conde de Campomanes.

Rousseau, J. (1762) Emilio o de la educación, Bs. As, Edaf, 2008.

Vargas Ponce, J. (1791) Declamación contra los abusos introducidos en el castellano. Madrid: Imprenta de la viuda de Ibarra. 


\section{¿Cómo citar este artículo?}

Domingo Perrupato, S. (Julio-diciembre, 2018). lustración y circulación de ideas pedagógicas en la monarquía hispánica. Revista humanidades, 8(2), 1-33. doi: http://dx.doi.org/10.15517/h.v\%vi\%i.28672 